\title{
Reason Analysis of the Gap between CRTS III Slab and Self-compacting Concrete
}

\author{
Kunteng Zhu \\ School of Civil Engineering \\ Central South University \\ Changsha, China \\ 306353043@qq.com \\ Zhiping Zeng * \\ School of Civil Engineering \\ Central South University \\ Changsha, China \\ 996510155@qq.com \\ * Corresponding Author
}

\begin{abstract}
This paper established mechanical analysis model of track structure including rail, track slab, door type tendon, self-compacting concrete and base according to the CRTSIII track slab structure characteristics, and analyzed the force condition between interface of track slab and selfcompacting concrete under different loads. After a series of laboratory testing, obtained the bonding strength between track slab and self-compacting concrete, ranged from $0.736 \mathrm{MPa}$ to $1.76 \mathrm{MPa}$, and analyzed the cause of the gap of slab edge, gap of slab center, gap under rail by compared it with the theoretical calculation value. Results show that the negative temperature gradient loads is the main cause leading to the gap of slab edge and the corner of slab is most vulnerable while the train loads and the positive temperature gradient loads are the main causes of the gap of slab center and gap under rail, and the position of $1.0 \mathrm{~m}$ away from the longitudinal of slab center and the edge of end-slab under the rail are most likely to get gap.
\end{abstract}

Keywords- CRTSIII Slab Ballastless Track; Interface; Gap; Cause Analysis;

\section{INTRODUCTION}

As the bond interface of new and old concrete between CRTSIII track slab and self-compacting concrete, layer may have internal potential defects, bond relies on the van der Waals force and mechanical bite force, besides, the void exists in concrete organization and the gap on

\author{
Bin $\mathrm{Wu}$ \\ School of Civil Engineering \\ Central South University \\ Changsha, China \\ 956310155@qq.com \\ Bin Liu \\ School of Civil Engineering \\ Central South University \\ Changsha, China \\ 269036993@qq.com
}

peripheral aggregate in loading process, which becomes the weakest link in the concrete [1-3]. Poor combination of old and new concrete, unsolidified pouring, temperature stress, shrinkage stress, volumetric shrinkage and creep, the external environment and train loads, etc. could make the gap between the track slab and self-compacting concrete layer[4-6]. According to the relevant literatures of along the lateral length and position of CRTSIII track slab damage situation investigation, three categories conditions of gap can be divided: condition of slab edge gap, condition of slab center gap and condition of gap under rail [7].

\section{CALCULATION MODEL AND RELATED PARAMETERS}

To study interlaminar mechanical characteristics of track structure, the CRTSIII track slab beam-body model was established by the finite element software ANSYS, the rail use beam element to simulate while track, slab, self-compacting concrete layer and hydraulic support layer use three-dimensional entity unit to simulate, as shown in fig $1^{[8-10]}$. The bonding destruction of the layer between track slab and self-compacting concrete use contact element to simulate. In reality, bonding failure between the layers are often accompanied by concrete damage so the damage of concrete uses the extinction unit of element birth and death to simulate.
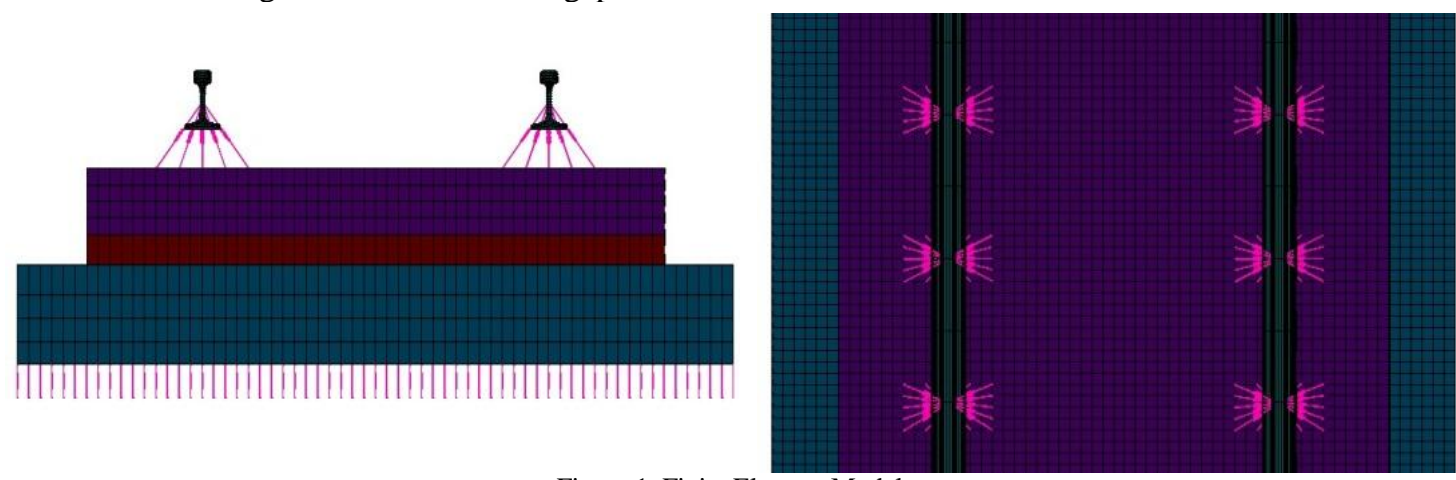

Figure 1. Finite Element Model 
In this model, the type of rail is $60 \mathrm{~kg} / \mathrm{m}$, the vertical stiffness of fastener is $50 \mathrm{kN} / \mathrm{m}$, the spacing of fasteners is $0.63 \mathrm{~m}$, the track slab is $0.2 \mathrm{~m}$ thick, $2.5 \mathrm{~m}$ wide and 5.6 $\mathrm{m}$ long, the Self-compacting concrete is $0.09 \mathrm{~m}$ thick and $2.5 \mathrm{~m}$ wide, the basement slab is $0.3 \mathrm{~m}$ thick and $3.1 \mathrm{~m}$ wide. The wheel load using uniaxial load form and taking the single wheel of $225 \mathrm{kN}$ as vertical load, the most unfavourable load acting on the border between gap area and non-gap area. The largest temperature gradient is $90^{\circ} \mathrm{C}$ $/ \mathrm{m}$ and the largest negative temperature gradient is $45^{\circ} \mathrm{C}$ $/ \mathrm{m}$. The commonly used temperature gradient is the half of the maximum temperature gradient. The common temperature gradient is to check the combined train loads [11].

\section{THE CALCULATION RESULTS AND ANALYSIS}

This section mainly analysis on the causes of gap from the numerical calculation.

\section{A. Causes of Slab Edge Gap}

Under the effection of negative temperature gradient, the slab corner, slab end and slab edge are in the vertical tensile stress as $0.43 \mathrm{MPa}$, the bonding strength of track slab and self-compacting concrete ranged from $0.736 \mathrm{MPa}$ to $1.76 \mathrm{MPa}$, as the bond interface of new and old concrete between CRTSIII track slab and self-compacting concrete layer may have internal potential defects, the poor

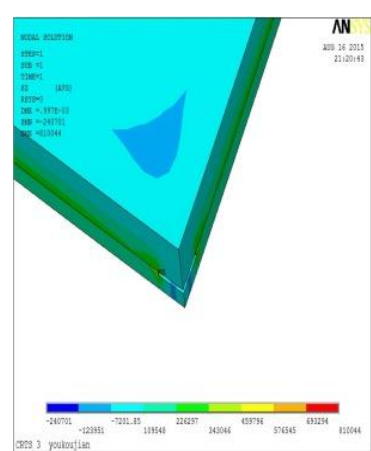

(a) case 1-a

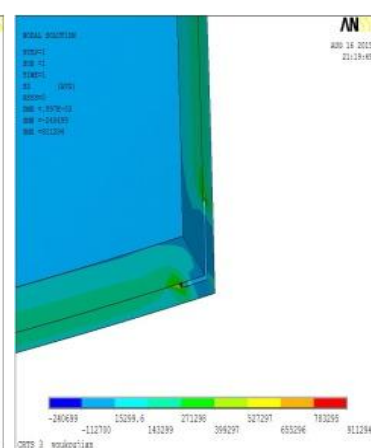

(b) case 1-b case 1-e
Figure 2. The Interface of Vertical Stress Cloud

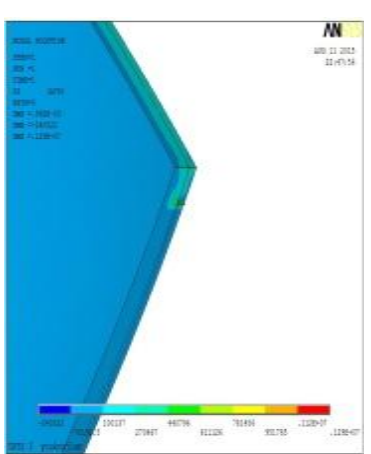

(c) case 1-e

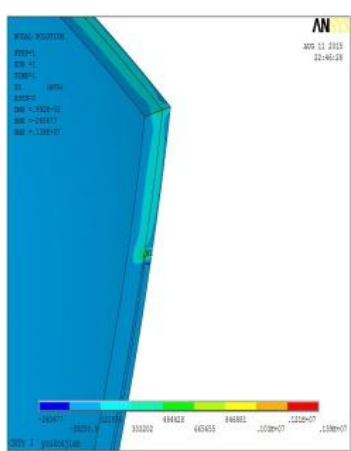

(d) case $1-f$

TABLE I. The Position and Size of the Vertical Stress(MPa)of the Interface

\begin{tabular}{|l|c|c|c|}
\hline \multicolumn{2}{|c|}{ CASE } & Maximum stress position & $\begin{array}{c}\text { Interface between slab and self } \\
\text { compacting concrete }\end{array}$ \\
\cline { 3 - 4 } Case 1-0 & Tensile stress & Slab angle & 0.43 \\
\hline Case 1-a & Tensile stress & The ends of slab & 0.81 \\
\hline Case 1-b & Tensile stress & Slab edges & 0.86 \\
\hline Case 1-c & Tensile stress & The ends of slab & 0.91 \\
\hline Case 1-d & Tensile stress & Slab edges & 1.02 \\
\hline Case 1-e & Tensile stress & The ends of slab & 1.1 \\
\hline Case 1-f & Tensile stress & Slab edges & 1.11 \\
\hline
\end{tabular}

\section{B. Causes of Slab Center Gap}

Under the coupling effect of the train load and positive temperature gradient, the interface between track slab and the self-compacting concrete is in the vertical tension, while the train loads is acting on a quarter of track slab, the interface between track slab and the self- combination of old and new concrete, unsolidified pouring, temperature stress, shrinkage stress, volumetric shrinkage and creep, the external environment and train , etc. could make the gap between the track slab and destruction between CRTSIII track slab layers happened, the tensile stress of slab corner would increase snificantly and the length of gap would increase further, 1-a to condition 1-f represents the gap on sla $0.3 \mathrm{~m} \times 0.3 \mathrm{~m}, \quad 0.4 \mathrm{~m} \times 0.3 \mathrm{~m}$. Select the compressive and tensile stress of track slab and selfcompacting concrete interface from the Figure 2, as shown in Table 1. According to Table 1, when the transverse and longitudinal length of gap is less than 0.4 $\mathrm{m}$, the gap area would develop along the shorter direction, hen the gap has the equally length in transverse and gap area would develop along the equal to $0.4 \mathrm{~m}$, because of the limitation of door tendons, the gap would develop along the longitudinal direction. 
Condition of 2-0 represents the intact interface while the specific meaning of condition 2-a to condition 2-g has shown in Figure 3, and the calculation results are shown in Figure 4. According to Figure 4, once the bonding destruction under the rail of CRTSIII track slab happened, the vertical stress gap developed to the underneath of first set of fasten, then the gap would develop along the slab center, when the gap developed to the underneath of third set of fastener, while the train loads is acting on a quarter of track slab, interface tension stress is lesser than the train loads acting on slab center as $1.53 \mathrm{MPa}$, and the gap would develop to slab center further, when the gap developed to the underneath of forth set of fastener, the maximum tensile stress appears in the $4.6 \mathrm{~m}$ of longitudinal and gap would develop to slab center, when the gap developed to the underneath of seventh set of fastener, the gap would develop to slab edge, when the gap developed to the underneath of ninth set of fastener, the gap would develop to slab center and in condition of longitudinal transfixion.

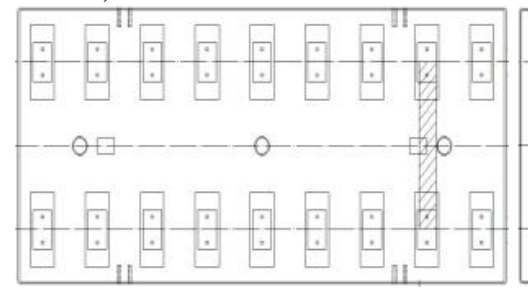

(a)case 2-a

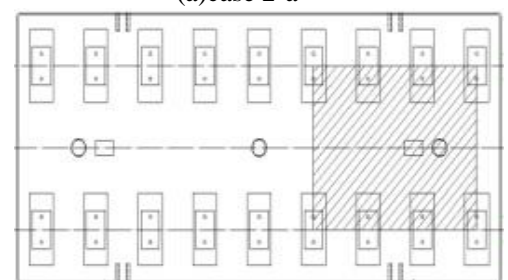

(d) case $2-d$

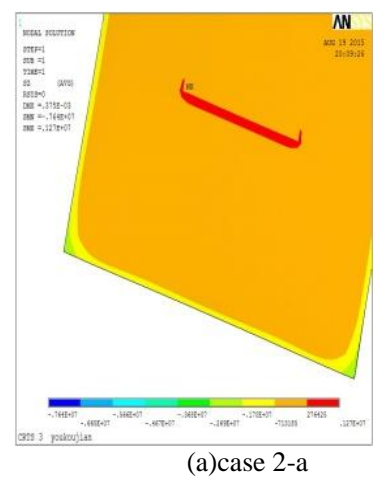

(a)case 2-a

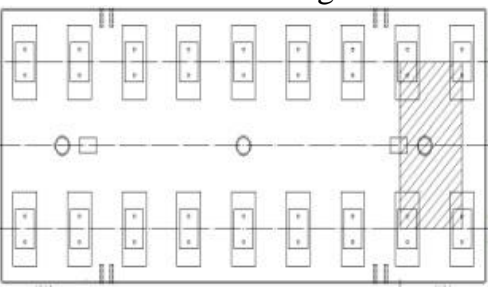

(b) case 2-b

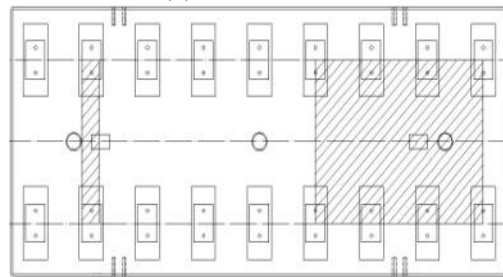

(e) case 2-e

Figure 3. The Gap Chart of Case 2-a to 2-f

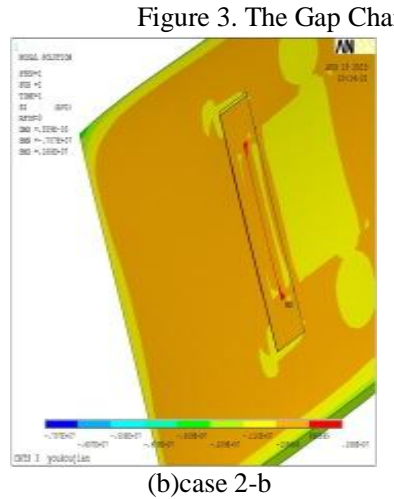

(b) case 2-b

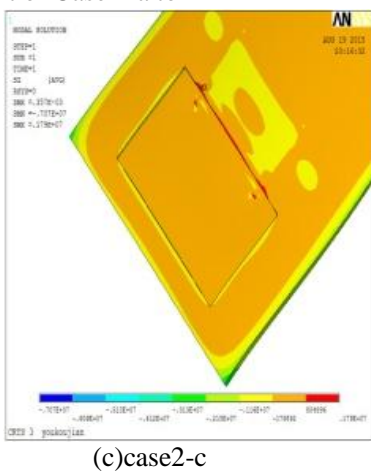

(c) case2-c
ical Stress Cloud (c) case $2-c$

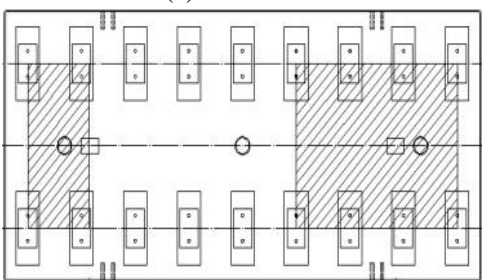

(f) case 2-f

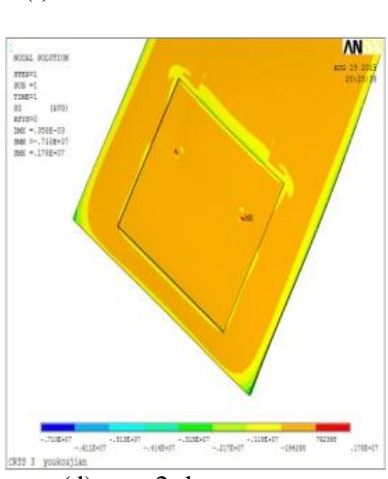

(d) case $2-d$

\section{Causes of Gap Under Rail}

Once the bonding destruction under the rail of CRTSIII track slab happened, the stress of interface between gap slab and the self-compacting concrete would increase significantly, Under the coupling effect of the train load (acting on slab center) and positive temperature gradient and the length of gap would increase further.

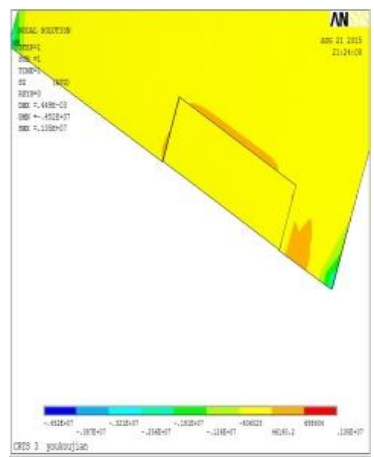

(a) case 3-1

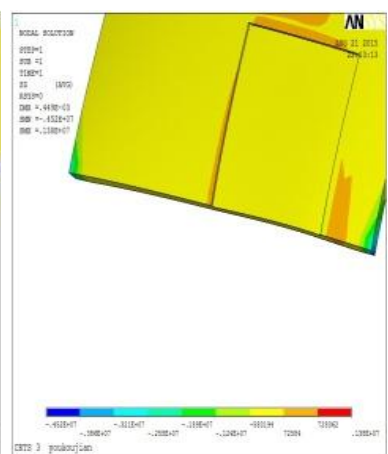

(b) case 3-2

Figure 5. The Interface of Vertical Stress Cloud

Condition of 3-1 to 3-9 represents the transverse of gap area is $0.7 \mathrm{~m}$ and the longitudinal of gap area is increasing stepwise with units of fastener spacing. The results as shown in figure 5 , according to the figure 5 , the stress of gap in longitudinal edge interface and the position of maximum stress position, as shown in table 2 .

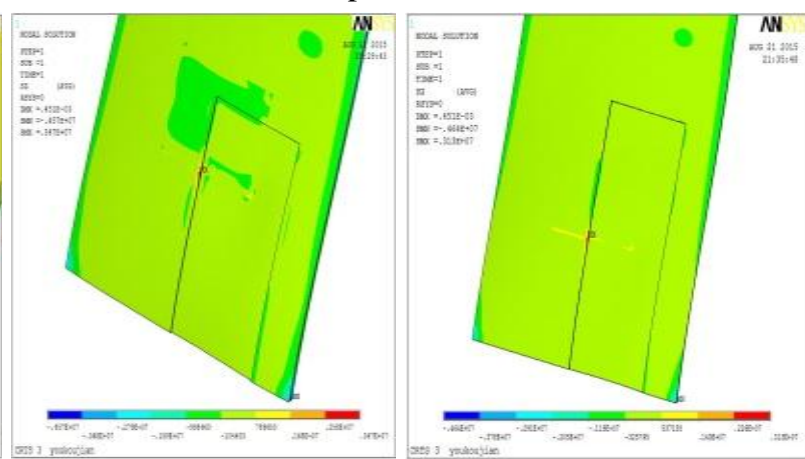

(d) case 3-4 
TABLE II. The Position and Size of the Vertical Stress(MPa)of the Interface

\begin{tabular}{|c|c|c|c|c|}
\hline \multicolumn{2}{|c|}{ CASE } & $\begin{array}{c}\text { Longitudinal edge } \\
\text { of the gap }\end{array}$ & Maximum stress position & $\begin{array}{c}\text { Interface between } \\
\text { slab and self } \\
\text { compacting concrete }\end{array}$ \\
\cline { 3 - 5 } Case 3-1 & Tensile stress & 0.69 & Longitudinal edge of the gap & 0.69 \\
\hline Case 3-2 & Tensile stress & 0.73 & Second sets of fasteners & 1.88 \\
\hline Case 3-3 & Tensile stress & 1.68 & Second sets of fasteners & 2.58 \\
\hline Case 3-4 & Tensile stress & 1.40 & Second sets of fasteners & 2.26 \\
\hline Case 3-5 & Tensile stress & 0.33 & Second sets of fasteners & 2.26 \\
\hline Case 3-6 & Tensile stress & 0.33 & Second sets of fasteners & 2.26 \\
\hline Case 3-7 & Tensile stress & 0.33 & Second sets of fasteners & 2.26 \\
\hline Case 3-8 & Tensile stress & 1.39 & Second sets of fasteners & 2.26 \\
\hline Case 3-9 & Tensile stress & 0.31 & Second sets of fasteners & 2.32 \\
\hline
\end{tabular}

\section{CONCLUSION}

(1) The negative temperature gradient loads are the main cause leading to the gap of slab edge and the corner of slab is the most vulnerable. When the horizontal and vertical length of gap is less than $0.4 \mathrm{~m}$, the gap area would develop along the shorter direction, when the gap has the equally length in horizontal and vertical, the gap area would develop along the vertical direction. when the horizontal length of gap is equal to $0.4 \mathrm{~m}$, because of the limitation of door tendons, the gap would develop along the vertical direction.

(2) The train loads and the positive temperature gradient loads are the main causes leading to the gap of slab center, and the position of $1.0 \mathrm{~m}$ away from the longitudinal of slab center is most likely to get gap. When the slab center gaps, with the different positions of train load, the length of gap would increase further.

(3) The train loads and the positive temperature gradient loads is the main cause of the gap under rail, and the edge of end-slab is most likely to get gap. When the edge of end-slab gaps, the interface stress would increase and gap develop to longitudinal.

\section{ACKNOWLEDGEMENTS}

The research described in this paper was financially supported by the Science and Technology Foundation of China Railway Corporation (Grant No. 2014G001-D); the Joint Funds of the National Natural Science Foundation of China (Grant Nos. U1334203 and U1434204); the
National Key Technology R\&D Program (Grant No. 2013BAG20BH00).

\section{REFERENCES}

[1] GAO Liang, ZHAO Lei, QU Cun, CAI Xiaopei. Analysis on Design Scheme of CRTS III Type Slab Ballastless Track [J]. Journal of Tongji University (Natural Science), 2013, 41(6): 848-855.

[2] MAN Kunlin, LONG Guangcheng, Xie Youjun. Carbonation and Mechanics Evolvement of Self-consolidating Concrete Used in CRTS III Type Slab Ballastless Track Filling Layer [J]. Journal of Railway Science and Engineering, 2012, 9(6): 42-47.

[3] WEI Hedao. Research on the Structure Design of New Unit Slab Ballastelss Track on the Zhengzhou-Xuzhou Railway Passenger Dedicated Line[D]. Changsha: Central South University, 2013.

[4] China Academy of Railway Sciences, Central South University. Performance Test Research of CRTS III Type Slab Ballastless Track Structures under Service State. Beijing: China Academy of Railway Sciences, 2015

[5] LI Yangcun. CRTS III Type Slab Track Technology Applied in Wuhan to Xianniing Intercity Railway[J]. Journal of Railway Engineering Society, 2013,15(4):51-55.

[6] WANG Pu, GAO Liang, ZHAO Lei, QUN Cun. Study on Setting Method of Position-limitation Recess of CRTS III Type Slab Ballastless Track[J]. Engineering Mechanics,2014, 31(2):110-115.

[7] YANG Zheng. Mechanics and Maintenance Standards of Connection Damage for CRTS III Slab Track[D]. Chengdu: Southwest Jiaotong University, 2011.

[8] WANG Yuhang, WANG Jijun. Multi-scale Finite Element Model for CRTS III Type Slab Ballastless Track Structures[J]. Journal of Railway Science and Engineering, 2015, 12(3): 468-474.

[9] WANG Xinmin. Numerical Analysis of Ansys Engineering structure[M]. Beijing: China Communications Press, 2007.

[10] ZHU Bofang. Application of the finite element method[M]. Beijing: China Water Power Press, 2004

[11] China Academy of Railway Sciences. General Reference Map of High Speed Railway CRTS III Type Slab Ballastless Track Structures[S]. Beijing: China Academy of Railway Sciences, 2015. 